\title{
Pulmonary Arterial Contractility in Neonatal Lambs Increases with $100 \%$ Oxygen Resuscitation
}

\author{
SATYAN LAKSHMINRUSIMHA, JAMES A. RUSSELL, ROBIN H. STEINHORN, RITA M. RYAN, SYLVIA F. GUGINO, \\ FREDERICK C. MORIN III, DANIEL D. SWARTZ, AND VASANTH H. KUMAR
}

\author{
Department of Pediatrics [S.L., J.A.R., R.M.R., S.Y.G., F.C.M., D.D.S., V.H.K.], Department of Physiology and Biophysics [J.A.R.], \\ University at Buffalo, Buffalo, New York, 14222; Department of Pediatrics [R.H.S.], Northwestern University,
}

Chicago, Illinois 60614

\begin{abstract}
The optimal $\mathrm{Fio}_{2}$ during neonatal resuscitation is a subject of controversy. The effect of exposure to high levels of inspired oxygen on pulmonary arterial (PA) contractility is not known. We studied differences in PA vasoreactivity in term lambs initially ventilated with $21 \%$ or $100 \%$ oxygen, followed by continued ventilation using oxygen as needed for $24 \mathrm{~h}$, or ventilated with $100 \%$ oxygen for $24 \mathrm{~h}$ and room air breathing 1-d-old lambs. Term lambs were delivered by cesarean section, intubated, and ventilated with $21 \%(21 \%$ Res) or $100 \%$ oxygen $(100 \%$ Res $)$ for the first $30 \mathrm{~min}$ of life. Subsequently, the ventilator $\mathrm{FiO}_{2}$ was adjusted to maintain $\mathrm{PaO}_{2}$ between 45 and $65 \mathrm{~mm} \mathrm{Hg}$ for $24 \mathrm{~h}$. Five lambs were ventilated continuously with $100 \%$ oxygen $(100 \% 24 \mathrm{~h})$. Six spontaneously breathing newborn lambs (RA Spont) were studied for comparison. Lambs were killed at $24 \mathrm{~h}$ of life and PA rings were isolated and contracted with norepinephrine (NE) and $\mathrm{KCl}$ and some were relaxed with $\mathrm{A} 23187$ and SNAP in tissue baths. $\mathrm{NE}$ and $\mathrm{KCl}$ induced contractions were highest in PA isolated from $100 \% 24 \mathrm{~h}$ lambs, and were significantly higher in $100 \%$ Res lambs than PA from $21 \%$ Res lambs. Contraction responses in PA from RA Spont lambs were similar to $21 \%$ Res lambs. Relaxations to A23187 and SNAP were similar among all ventilated groups. PA contractility to $\mathrm{NE}$ and $\mathrm{KCl}$ is increased following both brief $(30 \mathrm{~min})$ and prolonged $(24 \mathrm{~h})$ exposure to $100 \%$ oxygen during mechanical ventilation. In contrast, normoxic resuscitation and ventilation do not increase PA contractility. (Pediatr Res 59: 137-141, 2006)
\end{abstract}

$\mathrm{T}$ he extent of oxygen supplementation during optimal resuscitation of a newborn infant remains controversial. Oxygen plays a crucial role in mediating pulmonary vascular transition at birth and even small increases in fetal oxygenation (similar to or less than that induced by room air ventilation) result in a dramatic decrease in pulmonary vascular resistance (1-3). However, the debate regarding the use of oxygen for neonatal resuscitation has intensified in recent years. New arguments have been added to the debate as more and more data indicate that not only is room air as good as $100 \%$ oxygen for resuscitation but that even a brief exposure to pure oxygen at birth might be detrimental (4). It has been suggested that breathing $100 \%$ oxygen dilates constricted

Received April 25, 2005; accepted June 15, 2005.

Correspondence: Satyan Lakshminrusimha, M.D., Division of Neonatology, Women and Children's Hospital of Buffalo, 219 Bryant St., Buffalo, NY 14222; e-mail: slakshmi@buffalo.edu

Funded by American Academy of Pediatrics/Neonatal Resuscitation Program Grant \# 1040244 (V.H.K.) and HL\#54705 (R.H.S.). pulmonary arteries more efficiently than room air. However, ultrasound and direct estimation of pulmonary arterial pressure in asphyxiated piglets demonstrated that pulmonary hypertension normalized as quickly with room air as with $100 \%$ oxygen $(5,6)$.

NE constriction of pulmonary arteries isolated from fetal and neonatal animals after normal transition has been studied in detail (7-9). However, the effect of oxygen exposure during resuscitation and or ventilation on the contractile response to NE is not known.

We hypothesized that exposure to $100 \%$ oxygen during resuscitation would result in formation of reactive oxygen species and induce increased pulmonary arterial contractile response and that the increased contractility would be proportional to the duration of exposure to $100 \%$ oxygen. We also expected impaired relaxation responses to endotheliumdependent and -independent agents after exposure to $100 \%$ oxygen due to inactivation of nitric oxide by reactive oxygen species. We addressed these hypotheses using term lambs with varying levels of oxygen exposure.

\section{METHODS}

We studied the effect of resuscitation with $21 \%$ oxygen versus $100 \%$ oxygen for $30 \mathrm{~min}$ followed by normoxic ventilation for a total of $24 \mathrm{~h}$ on pulmonary arterial contraction to both receptor dependent and independent vasoconstrictors. Relaxations to endothelium dependent and independent vasodilators were also examined. We compared the constrictor responses to results obtained from pulmonary arteries isolated from normal 24-h-old lambs and newborn lambs ventilated with $100 \%$ oxygen for the entire $24 \mathrm{~h}$.

The Laboratory Animal Care Committee at the State University of New York at Buffalo approved this study. Near term gestation pregnant ewes (139 d gestation, term approximately $145 \mathrm{~d}$ ) were obtained from the Swartz family farm (Attica, NY). After $12 \mathrm{~h}$ of fasting, ewes were anesthetized with pentothal and halothane. Lambs were exteriorized by cesarean section. A small incision was made in the neck and systemic arterial and venous access was established through the carotid artery and jugular vein respectively. Lambs were intubated and then delivered. Lambs were sedated with fentanyl $2 \mu \mathrm{g} / \mathrm{kg} /$ dose every $2 \mathrm{~h}$ prn and received an initial dose of pancuronium bromide $0.1 \mathrm{mg} / \mathrm{kg} / \mathrm{dose}$ at birth, which was repeated only if necessary for vigorous spontaneous movement despite adequate sedation. Repeat dose of pancuronium bromide was required in approximately two lambs in each group. Only one extra dose was required in these lambs at approximately

Abbreviations: LNA, $\mathrm{N}_{\omega}$ nitro-L-arginine; NE, norepinephrine; $\mathbf{P A o}_{2}$, alveolar partial pressure of oxygen; PPHN, persistent pulmonary hypertension of newborn; SNAP, nitric oxide donor S-nitrosyl amino penicillamine

DOI: 10.1203/01.pdr.0000191136.69142.8c 
$8-14 \mathrm{~h}$ of life. They were placed under servo-controlled radiant warmers and rectal temperature was maintained between 37.9 and $39^{\circ} \mathrm{C}$. Intravenous fluids (dextrose $10 \%$ solution with $25 \mathrm{mEq}$ of sodium chloride, $20 \mathrm{mEq}$ of potassium chloride and $10 \mathrm{mEq}$ of sodium bicarbonate per liter) were administered continuously at $100 \mathrm{~mL} / \mathrm{kg} / \mathrm{d}$. Fluid composition and rate was adjusted based on serum electrolyte values. The lambs were ventilated with Servo 300 ventilators (Seimens, Mississauga, ON, Canada) with the following settings: positive end-expiratory pressure, 4 ; rate, 60/min; peak inspiratory pressure (PIP), approximately $25 \mathrm{~cm}$ of water (adjusted to deliver $10 \mathrm{~mL} / \mathrm{kg}$ tidal volume using a BiCore CP-100 Monitor, BiCore Monitoring systems, Irvine, CA). Arterial blood gases were monitored frequently (every 5-15 min) during initial stabilization. Ventilator settings (PIP and rate) were adjusted to maintain arterial $\mathrm{PCO}_{2}$ between 35 and $50 \mathrm{~mm} \mathrm{Hg}$. A neonatologist, neonatal fellow, neonatal nurse practitioner, or neonatal nurses from the Women and Children's Hospital of Buffalo provided continuous care for the lambs.

The lambs were assigned to the following groups: i) newborn lambs (approximately $24 \mathrm{~h}$ after vaginal delivery, usually at 145-147 d gestation) obtained directly from the farm [room air spontaneous (RA Spont) group, $n=$ 6]; ii) ventilated with $21 \% \mathrm{O}_{2}$ for 30 min (arbitrarily called "resuscitation") followed by adjustment of $\mathrm{Fio}_{2}$ for $24 \mathrm{~h}$ to maintain $\mathrm{PaO}_{2}$ between 45 and 65 $\mathrm{mm} \mathrm{Hg}(21 \%$ Res group, $n=6)$, iii) ventilated with $100 \% \mathrm{O}_{2}$ for $30 \mathrm{~min}$, followed by adjustment of $\mathrm{Fio}_{2}$ to maintain $\mathrm{PaO}_{2}$ between 45 and $65 \mathrm{~mm} \mathrm{Hg}$ (100\%Res group, $n=6$ ), iv) ventilated with $100 \% \mathrm{O}_{2}$ for $24 \mathrm{~h}$, without any adjustment of $\mathrm{FiO}_{2}(100 \% 24 \mathrm{~h}$ group, $n=5$ ).

The $\mathrm{FiO}_{2}$ weaning protocol in the $100 \%$ Res group was as follows: After 30 min of ventilation with $100 \%$ oxygen, an arterial blood gas was obtained every $30 \mathrm{~min}$. The difference in actual $\mathrm{PaO}_{2}$ and target $\mathrm{PaO}_{2}(65 \mathrm{~mm} \mathrm{Hg})$ was calculated. This number was divided by 7 (based on $100 \%$ oxygen - alveolar $\mathrm{Po}_{2}$ of approximately $700 \mathrm{~mm} \mathrm{Hg}$ and that weaning by $1 \%$ should decrease $\mathrm{PaO}_{2}$ by $7 \mathrm{~mm} \mathrm{Hg}$ in the absence of lung disease) and oxygen concentration was weaned by this number. For example, if $\mathrm{PaCO}_{2}$ was $275 \mathrm{~mm} \mathrm{Hg}$ with $70 \%$ oxygen, oxygen was weaned by $30 \%$ and blood gas repeated in $30 \mathrm{~min}$. (275 $-65=210 / 7=30 \%$ ). The actual trend $\mathrm{in}^{\mathrm{Fio}} \mathrm{F}_{2}$ wean is shown in Figure 1 .

After $24 \mathrm{~h}$ of ventilation, lambs were anesthetized with pentothal sodium and killed by rapid exsanguinations through a direct cardiac puncture. The heart and lungs were removed en bloc and fifth-generation pulmonary arteries (inner diameters of $500 \mu \mathrm{m}$ ) were dissected, isolated, and cut into rings as described previously (10). Rings were suspended in water-jacketed chambers filled with aerated $\left(94 \% \mathrm{O}_{2}-6 \% \mathrm{CO}_{2}\right)$ modified Krebs-Ringer solution (118 $\mathrm{mM}$ sodium chloride, $4.7 \mathrm{mM}$ potassium chloride, $2.5 \mathrm{mM}$ calcium chloride, $1.2 \mathrm{mM}$ magnesium sulfate, $1.2 \mathrm{mM}$ potassium biphosphate, $25.5 \mathrm{mM}$ sodium bicarbonate, and $5.6 \mathrm{mM}$ glucose). A continuous recording of isometric force generation was obtained by tying each vessel ring to a force displacement transducer (model UC2, Statham Instruments, Hato Rey, PR) that was connected to a recorder (Gould Instrument Systems, Valley View, OH). After the arterial rings were mounted, they were allowed to equilibrate for $20 \mathrm{~min}$ in the bathing solution. A micrometer was used to stretch the tissues repeatedly in small increments over the following $45 \mathrm{~min}$ until resting tone remained stable

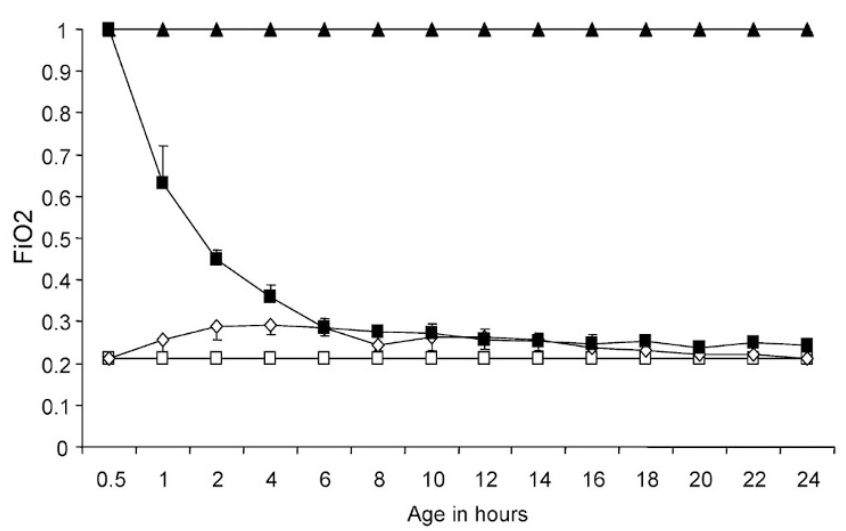

Figure 1. Four groups of lambs, based on oxygen exposure are shown in this figure where $\mathrm{FiO}_{2}$ is plotted on the $\mathrm{Y}$-axis and $\mathrm{X}$-axis shows age in hours. Term lambs were ventilated with $21 \%$ oxygen ( $21 \%$ Res: $\diamond, n=6)$, or $100 \%$ oxygen (100\%Res: $\square, n=6$ ), for the first $30 \mathrm{~min}$ of life. Subsequently, oxygen was adjusted and both these groups were managed similarly with a target $\mathrm{PaO}_{2}$ of $45-65 \mathrm{~mm} \mathrm{Hg}$ for $24 \mathrm{~h}$. Lambs ventilated continuously with $100 \%$ oxygen for $24 \mathrm{~h}(100 \% 24 \mathrm{~h}: \boldsymbol{\Delta}, n=5)$, and spontaneously breathing newborn lambs delivered at the farm (RA Spont: $\square, n=6$ ) were studied for comparison. All lambs were killed at $24 \mathrm{~h}$ of life. at a passive tension of $0.8 \mathrm{~g}$. Preliminary experiments determined that this procedure provided optimal length for generation of active tone to exogenous NE. Wet tissue weights were obtained at the end of each experiment, and contraction responses were normalized to tissue weight.

The following pharmacological agents were used: indomethacin, DLpropranolol, norepinephrine hydrochloride (NE), calcium ionophore A23187 and SNAP, and nitric oxide synthase antagonist, LNA. All drugs were obtained from Sigma-Aldrich (St. Louis, MO). SNAP was dissolved first in a small quantity of DMSO and then diluted in distilled water. Indomethacin was dissolved in ethanol and LNA was dissolved in warmed Kreb's solution. All other drugs were dissolved in distilled water. Ethanol and DMSO, at the concentrations used in these experiments, did not alter the preexisting tone of the pulmonary arteries.

Isolated pulmonary arteries were pretreated with indomethacin $\left(10^{-5} \mathrm{M}\right)$ to prevent the formation of vasoactive prostaglandins, and propranolol $\left(10^{-6}\right.$ M) to block $\beta$-adrenergic receptors. The arteries were first constricted with increasing doses of NE $\left(10^{-8}\right.$ to $\left.10^{-6} \mathrm{M}\right)$. The arteries were then washed, and when their tone returned to baseline, constricted with $118 \mathrm{mM}$ of potassium chloride. Constriction responses were recorded as gram force and were normalized for wet arterial ring weight (expressed as grams of force/grams weight). Four to six rings were studied from each animal and the mean contraction from these rings was used for analysis. In some lambs, two additional arterial rings were used for relaxation studies: these vessels were constricted with an EC50 concentration of NE and relaxed with increasing concentrations of either A23187 $\left(10^{-8}\right.$ to $\left.10^{-6} \mathrm{M}\right)$ or SNAP $\left(10^{-8}\right.$ to $10^{-5}$ $\mathrm{M})$. The vessels used in the SNAP relaxation studies were pretreated with LNA to block endogenous nitric oxide synthesis. These experiments were done in a dark room as LNA is sensitive to light.

All data are expressed as mean \pm SEM, with $n$ representing the number of animals studied. Statistical comparisons of the curves were performed with factorial or repeated measures ANOVA as appropriate. Student-NewmanKeuls posthoc testing was used as needed to compare multiple groups. All statistical analysis was performed with StatView software (Abacus Concepts, Berkley, CA). Significance was accepted at $p<0.05$.

\section{RESULTS}

Oxygen exposure. The $\mathrm{Fio}_{2}$ trend the in different groups of lambs is shown in Figure 1. Using the alveolar gas equation, the $\mathrm{PO}_{2}$ in the alveoli $\left(\mathrm{PAO}_{2}\right)$ was calculated and is shown in Figure 2. The $\mathrm{PAo}_{2}$ in RA Spont group was estimated based on arterial blood gases obtained from two lambs before sacrifice. By design, the lambs in the $100 \%$ Res group had significantly higher $\mathrm{PaO}_{2}$ than the $21 \%$ Res group during the first 30 min of life. The $\mathrm{Fio}_{2}$

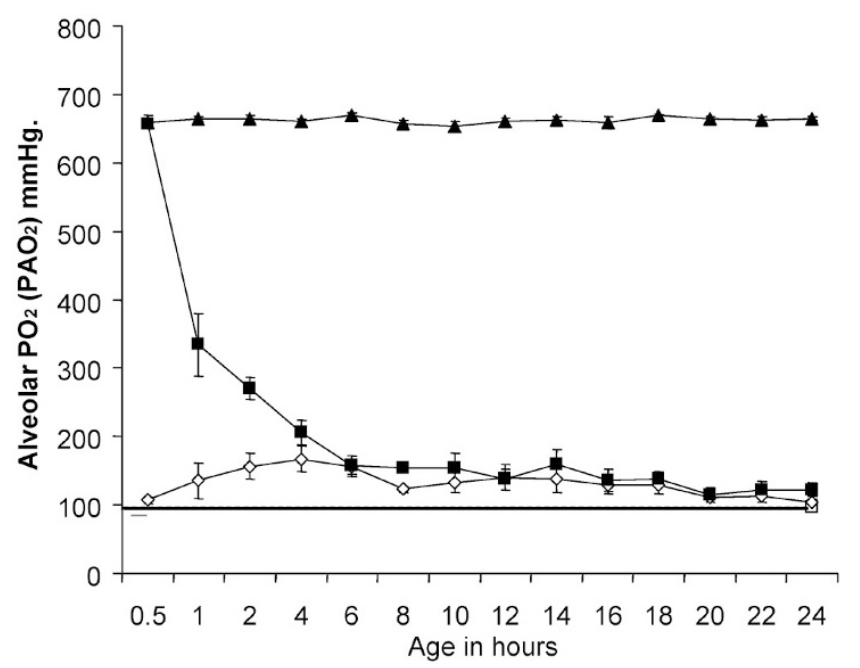

Figure 2. Calculated $\mathrm{PO}_{2}$ in the alveolar gas in the four groups of lambs depicted as mean ( \pm SEM) over age in hours. In spontaneously breathing lambs $(\square, n=$ 2 ), one arterial gas was obtained before sacrifice and these results were extrapolated back over the 24-h period (dashed line). The 100\%24h group $(\boldsymbol{\Lambda}, n=5)$ was exposed to significantly more oxygen than the $21 \% \operatorname{Res}$ lambs $(\diamond, n=6)$ throughout the 24 -h period. The $100 \% \operatorname{Res}$ group $(\boldsymbol{\square}, n=6)$ was exposed to more oxygen than the $21 \%$ Res lambs for the first $4 \mathrm{~h}$ of life. 
was gradually weaned over the next $3-4 \mathrm{~h}$ to approximately $0.25-0.30$. The lambs in the $21 \%$ Res group had relatively normal $\mathrm{PaO}_{2}$ of $104-156 \mathrm{~mm} \mathrm{Hg}$ throughout the study.

Arterial oxygenation. During the first $30 \mathrm{~min}$, arterial oxygenation was significantly different between the groups (Fig. 3). The mean $\left( \pm\right.$ SEM) $\mathrm{PAo}_{2}$ during the first 30 min was $49 \pm 7$, $285 \pm 47$, and $449 \pm 38 \mathrm{~mm} \mathrm{Hg}$ in the $21 \%$ Res, $100 \%$ Res, and $100 \% 24 \mathrm{~h}$ groups, respectively. At the end of the 24 -h period, the mean $( \pm \mathrm{SEM}) \mathrm{PAo}_{2}$ was $56 \pm 7,56 \pm 8$, and $444 \pm 29 \mathrm{~mm} \mathrm{Hg}$ in $21 \%$ Res, $100 \%$ Res, and $100 \% 24 \mathrm{~h}$ groups, respectively. The mean $\mathrm{PaO}_{2}$ value measured in the two spontaneously breathing lambs before sacrifice (RA Spont group) was $55 \mathrm{~mm} \mathrm{Hg}$.

Isolated vessel data. The wet pulmonary arterial ring weights were similar between the four groups. Cumulative NE concentration-response curves are shown in Figure 4. Pulmonary arteries isolated from $100 \%$ Res and $100 \% 24 \mathrm{~h}$ lambs showed significantly greater contraction to NE than 21\%Res and RA Spont lambs.

The pulmonary arterial contractions to $10^{-6} \mathrm{M}$ of NE and $118 \mathrm{mM}$ of potassium chloride from all the four groups of lambs are compared in Figure 5. Pulmonary arteries isolated from spontaneously room air breathing lambs (RA Spont) contracted similarly to $21 \%$ Res lambs in response to both NE and potassium chloride. Pulmonary arteries isolated from $100 \%$ Res lambs contracted significantly more than the $21 \%$ Res group. Pulmonary arteries isolated from $100 \% 24 \mathrm{~h}$ lambs contracted to a significantly higher degree to potassium chloride than the other three groups.

Relaxation responses to the calcium ionophore, A23187 and nitric oxide donor, SNAP were studied in the isolated pulmonary arteries. We and others have previously shown that A23187 stimulates endothelial nitric oxide synthase at low concentrations and relaxes pulmonary arteries $(11,12)$. At $10^{-8}$ to $10^{-6} \mathrm{M}$ concentrations, A23187 relaxed pulmonary arteries isolated from all groups in a similar manner (Fig. 6). Relaxation responses to SNAP were similar between the three ventilated groups (Fig. 7). In contrast, pulmonary arteries isolated from the RA Spont group relaxed significantly better to SNAP.

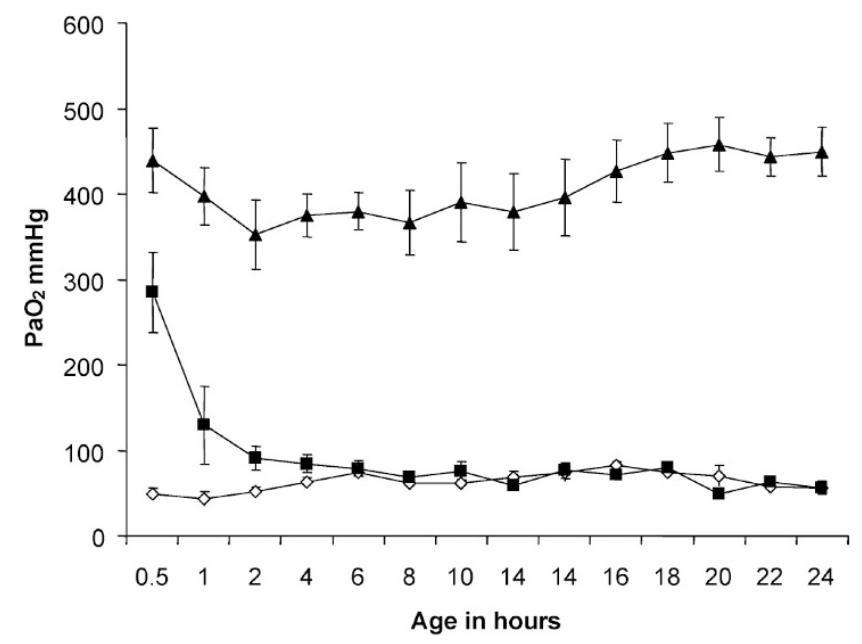

Figure 3. Arterial oxygenation (mean $\mathrm{PaO}_{2} \pm \mathrm{SEM}$ ) changes over time in three groups of lambs. The $100 \% 24 \mathrm{~h}$ group $(\boldsymbol{\Lambda}, n=5)$ had significantly higher $\mathrm{PaO}_{2}$ levels than both the resuscitation groups throughout the period of study. The $100 \%$ Res group $(\boldsymbol{\square}, n=6)$ had significantly higher $\mathrm{PaO}_{2}$ than the $21 \%$ Res group ( $\diamond, n=6$ ) for the first $4 \mathrm{~h}$ of life.

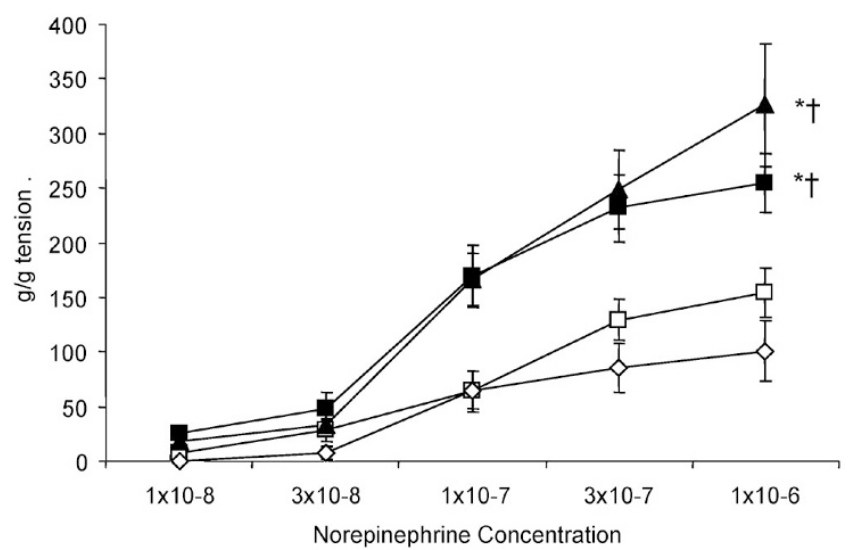

Figure 4. Cumulative dose response curves to norepinephrine in pulmonary arteries isolated from 24-h-old lambs. Exposure to oxygen either during the

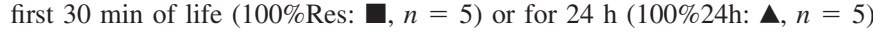
resulted in significantly increased contraction response compared with lambs resuscitated in room air (21\%Res: $\diamond, n=5$ ). Lambs spontaneously breathing room air $(\square, n=6)$ did not significantly differ from the $21 \%$ Res group (* $p$ $<0.05$ compared with $21 \%$ Res, ${ }^{\dagger} p<0.05$ compared with RA Spont, by ANOVA repeated measures).

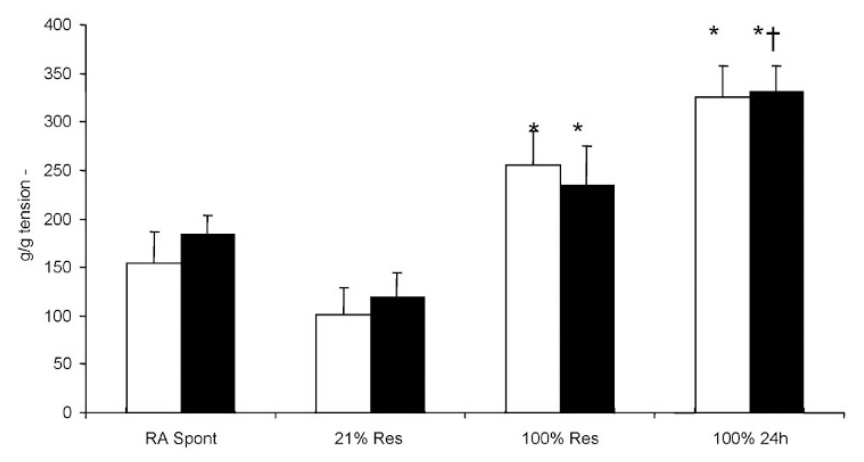

Figure 5. Contractions to $10^{-6} \mathrm{M}$ of norepinephrine (ם) and $118 \mathrm{mM}$ of potassium chloride $(\square)$ of isolated pulmonary arterial rings measured as grams of tension per gram arterial ring weight. $\left({ }^{*} p<0.05\right.$ compared with $21 \%$ Res pulmonary arteries; ${ }^{\dagger} p<0.05$ compared with $100 \%$ Res pulmonary arteries by ANOVA Student-Newman-Keuls posthoc test). $n=6$ lambs in RA Spont group; $n=5$ each in $21 \%$ Res, $100 \%$ Res, and 100\%24h groups).

\section{DISCUSSION}

We have demonstrated that even a brief exposure to $100 \%$ oxygen is adequate to significantly increase the contraction of fifth generation pulmonary arteries to NE and potassium chloride $24 \mathrm{~h}$ later. Our group and others have studied vascular reactivity of pulmonary arteries isolated from fetal, neonatal, juvenile, and adult animals extensively $(7-9,13)$. However, to our knowledge, no data are available on changes in pulmonary vascular reactivity after conventional gas ventilation. By design, lambs in the $100 \%$ Res group were exposed to higher oxygen during the first few hours of life (Figs. 1 and 2). For the subsequent $19-20 \mathrm{~h}$ of the $24-\mathrm{h}$ ventilation period, $100 \%$ Res and $21 \%$ Res groups were exposed to similar amounts of oxygen. As expected, the alveolar and arterial oxygen levels were similar in both groups during this later period (Figs. 2 and 3).

Considering spontaneous delivery and breathing room air as the gold standard, baseline NE and potassium chloride constriction data were obtained in pulmonary arteries isolated from 


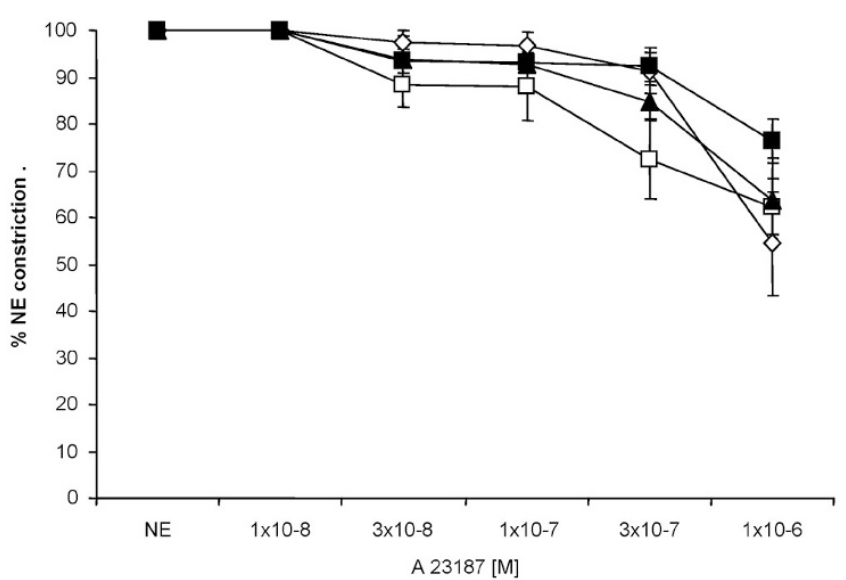

Figure 6. Cumulative concentration response curves to calcium ionophore and endothelial nitric oxide synthase agonist A23187 in pulmonary arteries isolated from 24-h-old lambs. Relaxation responses were similar in all four groups of lambs. RA Spont: $\square, n=3$; 21\%Res: $\diamond, n=5$; 100\%Res: $\mathbf{\square}$, $n=4 ; 100 \% 24 \mathrm{~h}: \mathbf{\Delta}, n=4 ; p>0.05$ by ANOVA repeated measures.

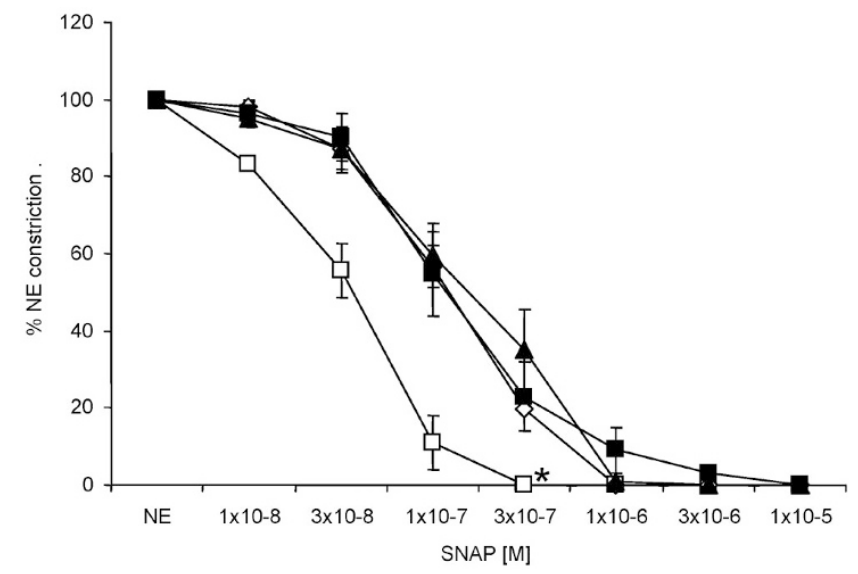

Figure 7. Cumulative concentration response curves to nitric oxide donor, SNAP in pulmonary arteries isolated from 24-h-old lambs. Pulmonary arteries isolated from $21 \% \operatorname{Res}(\diamond, n=3), 100 \% \operatorname{Res}(\boldsymbol{\square}, n=4)$, and $100 \% 24 \mathrm{~h}$ $(\boldsymbol{\Lambda}, n=4)$ groups of lambs relaxed in a similar fashion to SNAP. In contrast, pulmonary arteries isolated from RA Spont $(\square, n=3)$ group relaxed significantly better to SNAP. $\left({ }^{*} p<0.05\right.$ by ANOVA repeated measures compared with $100 \%$ Res).

1-d-old lambs (Fig. 5). Pulmonary arteries obtained from lambs ventilated with $100 \%$ oxygen for $24 \mathrm{~h}(100 \% 24 \mathrm{~h})$ generated significantly more tension with NE and potassium chloride. Even a brief 30-min exposure to $100 \%$ oxygen in the $100 \%$ Res group resulted in pulmonary arterial contractility that was greater than $21 \%$ Res lambs but less than $100 \% 24$ h lambs. Because the $21 \%$ Res group did not differ significantly from spontaneously room air breathing lambs (RA Spont group), we suggest that oxygen exposure and not ventilation was the factor responsible for increasing pulmonary arterial contractility.

We speculate that the increased contractile response in lambs exposed to $100 \%$ oxygen is secondary to the formation of reactive oxygen species in the pulmonary arteries. Hyperoxic exposure can result in increased superoxide anion formation in the airway (Fig. 8). Excess superoxide may react directly with nitric oxide, disrupting its physiologic signaling. However, we did not observe a difference in responses to exogenous NO (delivered as SNAP) in the $21 \%$ Res versus $100 \%$ groups, indi-

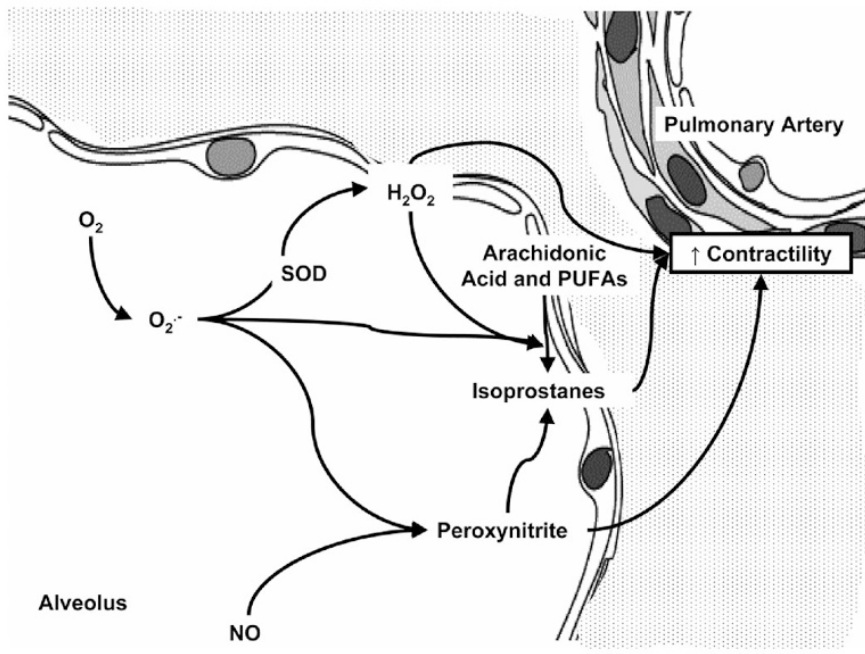

Figure 8. Hypothesized role of reactive oxygen species and their metabolites in mediating increased pulmonary arterial contractility following exposure to $100 \%$ oxygen. Exposure to high oxygen concentrations results in formation of superoxide anions $\left(\mathrm{O}_{2}{ }^{-}\right)$. Superoxide anions combine with nitric oxide (NO) to form peroxynitrite, a potent pulmonary vasoconstrictor. Superoxide dismutase (SOD) enzyme converts superoxide anions to hydrogen peroxide $\left(\mathrm{H}_{2} \mathrm{O}_{2}\right)$, also a pulmonary vasoconstrictor. When membrane lipids (arachidonic acid and poly unsaturated fatty acids, PUFA) are exposed to reactive oxygen species such as superoxide anions and hydrogen peroxide or peroxynitrite, a variety of isoprostanes are formed. Isoprostanes are known constrictors of pulmonary arteries.

cating this direct interaction was not a likely explanation. In the presence of superoxide dismutase, hydrogen peroxide may be formed. Hydrogen peroxide is relatively stable and diffusible compared with many other reactive oxygen species, and has been reported to elicit pulmonary arterial constriction depending on the concentration and length of exposure (14).

Other possible agents mediating vasoconstriction include peroxynitrite and isoprostanes (Fig. 8). Superoxide anions combine with endogenous nitric oxide with high affinity to form toxic peroxynitrite (15). Peroxynitrite has been shown to be a potent vasoconstrictor of newborn but not adult pulmonary arteries from rats (16), possibly mediated by formation of isoprostanes (17). Elevated tracheal aspirate isoprostane levels have been reported in babies ventilated with high levels of oxygen compared with those ventilated with room air (18). Isoprostanes generated more contraction force in newborn rats exposed to oxygen (19).

Preliminary data from our laboratory indicate that one dose of intratracheal recombinant human superoxide dismutase (rhSOD) administered to lambs at birth partly prevents the increased pulmonary arterial contractile response to NE $\left(10^{-6} \mathrm{M}\right)$ seen following $24 \mathrm{~h}$ of ventilation with $100 \%$ oxygen $(267 \pm 26.3 \mathrm{~g} / \mathrm{g}$ constriction with rhSOD $+100 \% 24 \mathrm{~h}$ compared with $326.6 \pm$ $33.4 \mathrm{~g} / \mathrm{g}$ in $100 \% 24 \mathrm{~h}$ group) (20). Dismutation of superoxide anions by intratracheal superoxide dismutase may decrease reactive oxygen species and/or prevent peroxynitrite formation and increase bioavailability of endogenous nitric oxide resulting in decreased pulmonary arterial contraction.

Endothelium dependent relaxations to A23187 were similar in pulmonary arteries isolated from all the groups (Fig. 6) contrary to our hypothesis. Therefore, we conclude that changes in endothelial nitric oxide synthase activity are un- 
likely to contribute to increased contractions noted in pulmonary arteries isolated from $100 \%$ Res lambs. Relaxations to the endothelium independent agent, SNAP were impaired in $21 \%$ Res, $100 \%$ Res, and $100 \% 24 \mathrm{~h}$ group pulmonary arteries compared with the RA Spont group (Fig. 7). Similar impairment in sodium nitroprusside-mediated relaxations has been observed following liquid ventilation in preterm lambs (13). These findings may indicate that mechanical ventilation, and not oxygen exposure, induces changes in smooth muscle reactivity. The increased gestational age of the RA Spont group of lambs at birth (145-147 d versus $139 \mathrm{~d}$ in ventilated groups) and the effect of spontaneous labor and vaginal delivery may also play a role in altered vasoreactivity.

What is the significance of these observations? Pulmonary arterial $\mathrm{Po}_{2}$ in fetal lambs is approximately $20 \mathrm{~mm} \mathrm{Hg}(21)$. With room air ventilation at birth, $\mathrm{PaO}_{2}$ increases by 7 - to 8 -fold to $140-150 \mathrm{~mm} \mathrm{Hg}$ and is adequate to mediate the significant decrease in pulmonary vascular resistance at birth. Ventilation with $100 \%$ oxygen results in $\mathrm{Pao}_{2}$ levels $>600$ $\mathrm{mm} \mathrm{Hg}$ ( $>30$-fold increase) and may induce oxidative damage. Human trials have shown that brief exposure to oxygen during resuscitation resulted in prolonged biochemical changes lasting $28 \mathrm{~d}$ (22). After resuscitation with $100 \%$ oxygen, the pulmonary arterial smooth muscle may be subject to oxidative injury resulting in higher contractile response to an additional vasoconstrictor stimulus. We are currently conducting in vivo studies to further explore this issue.

We acknowledge several drawbacks in this study. We designed the study to compare two groups of lambs that differed with respect to initial oxygen exposure for $30 \mathrm{~min}$ only. Ventilating lambs for $30 \mathrm{~min}$ in room air or oxygen is not "resuscitation" in the strict sense of this word in day-today pediatric practice. However, this study design gave us a controlled environment for first $24 \mathrm{~h}$ of life and is similar to other animal experiments studying oxygen resuscitation (6).

Many laboratories (including ours) that study isolated vessels in conventional tissue baths use a $94 \%$ oxygen and $6 \% \mathrm{CO}_{2}$ gas mixture $(8,23,24)$. The $\mathrm{Po}_{2}$ of the buffer solution bathing the tissue is close to $500 \mathrm{~mm} \mathrm{Hg}$ and $\mathrm{PCO}_{2}$ is approximately $40 \mathrm{~mm}$ Hg. This approach was based on the assumption that the inner core of smooth muscle cells in the vessel may be relatively hypoxic because of lack of perfusion through the vasa vasorum. However, we considered the possibility that a high-buffer $\mathrm{PO}_{2}$ might affect our results. We found that using $94 \%$ room air and $6 \% \mathrm{CO}_{2}$ still resulted in $\mathrm{Po}_{2}$ of $125 \mathrm{~mm} \mathrm{Hg}$ in the vessel bath, higher than the arterial $\mathrm{Po}_{2}$ and considerably above the $\mathrm{Po}_{2}$ in the pulmonary arteries in vivo. Further, bubbling the tissue bath with $94 \%$ nitrogen and $6 \% \mathrm{CO}_{2}$ resulted in a $\mathrm{Po}_{2}$ of $60-65 \mathrm{~mm} \mathrm{Hg}$, probably from equilibration with room air. Preliminary experiments in our isolated vessel systems using 94\% nitrogen and 6\% $\mathrm{CO}_{2}$ gas mixture did not reveal significant differences in contraction to NE or potassium chloride or relaxations to A23187 and SNAP. In fact, pulmonary arterial segments from two animals from each ventilated group were studied in baths bubbled with $94 \%$ nitrogen and $6 \% \mathrm{CO}_{2}$. The mean $\mathrm{g} / \mathrm{g}$ constriction response to $10^{-6} \mathrm{M}$ concentration of $\mathrm{NE}$ was 139,232 , and $290 \mathrm{~g} / \mathrm{g}$ from $21 \%$ Res, $100 \%$ Res, and $100 \% 24 \mathrm{~h}$ pulmonary arteries, respec- tively, in $94 \%$ nitrogen baths (similar to 101, 255, and $326 \mathrm{~g} / \mathrm{g}$, respectively, noted in $94 \%$ oxygen and $6 \% \mathrm{CO}_{2}$ baths).

We conclude that even brief exposure to $100 \%$ oxygen at birth results in increased contractile responses of isolated pulmonary arteries to vasoconstrictor agents. Further experiments need to be conducted to understand the mechanisms for, and potential significance of, this important finding.

Acknowledgments. The authors thank Karen Wynn, NNP, Huamei Wang, M.D., Nasir Rashid, M.D., Margaret Brick, Jan Capell, RN, and Sharon Baumgartner for their expert technical assistance during ventilation studies.

\section{REFERENCES}

1. Morin FC 3rd, Egan EA 1992 Pulmonary hemodynamics in fetal lambs during development at normal and increased oxygen tension. J Appl Physiol 73:213-218

2. Abman SH, Chatfield BA, Hall SL, McMurtry IF 1990 Role of endothelium-derived relaxing factor during transition of pulmonary circulation at birth. Am J Physiol 259:H1921-H1927

3. Tiktinsky MH, Morin FC 3rd 1993 Increasing oxygen tension dilates fetal pulmonary circulation via endothelium-derived relaxing factor. Am J Physiol 265:H376-H380

4. Saugstad OD 2004 The role of oxygen in neonatal resuscitation. Clin Perinatol 31:431-443

5. Fugelseth D, Borke WB, Lenes K, Saugstad OD 2004 Room air is as efficient as $100 \%$ oxygen in reversing hypoxemia-induced cardiovascular effects in newborn pigs. Pediatr Res 54:618A

6. Medbo S, Yu XQ, Asberg A, Saugstad OD 1998 Pulmonary hemodynamics and plasma endothelin-1 during hypoxemia and reoxygenation with room air or $100 \%$ oxygen in a piglet model. Pediatr Res 44:843-849

7. Dunn JA, Lorch V, Sinha SN 1989 Responses of small intrapulmonary arteries to vasoactive compounds in the fetal and neonatal lamb: norepinephrine, epinephrine, serotonin, and potassium chloride. Pediatr Res 25:360-363

8. Schindler MB, Hislop AA, Haworth SG 2004 Postnatal changes in response to norepinephrine in the normal and pulmonary hypertensive lung. Am J Respir Crit Care Med 170:641-646

9. Belik J 1995 The myogenic response of arterial vessels is increased in fetal pulmonary hypertension. Pediatr Res 37:196-201

10. Steinhorn RH, Morin FC 3rd, Gugino SF, Giese EC, Russell JA 1993 Developmental differences in endothelium-dependent responses in isolated ovine pulmonary arteries and veins. Am J Physiol 264:H2162-H2167

11. Gao Y, Zhou H, Raj JU 1995 Endothelium-derived nitric oxide plays a larger role in pulmonary veins than in arteries of newborn lambs. Circ Res 76:559-565

12. Steinhorn RH, Russell JA, Morin FC 3rd 1995 Disruption of cGMP production in pulmonary arteries isolated from fetal lambs with pulmonary hypertension. Am J Physiol 268:H1483-H1489

13. Villamor E, Degraeuwe PL, De Mey JG, Blanco CE 2003 Vascular reactivity of pulmonary arteries from premature lambs subjected to liquid ventilation. Biol Neonate 84:172-178

14. Sheehan DW, Giese EC, Gugino SF, Russell JA 1993 Characterization and mechanisms of H2O2-induced contractions of pulmonary arteries. Am J Physiol 264:H1542-H1547

15. Faraci FM, Didion SP 2004 Vascular protection: superoxide dismutase isoforms in the vessel wall. Arterioscler Thromb Vasc Biol 24:1367-1373

16. Belik J, Jankov RP, Pan J, Tanswell AK 2004 Peroxynitrite inhibits relaxation and induces pulmonary artery muscle contraction in the newborn rat. Free Radic Biol Med 37:1384-1392

17. Janssen LJ, Catalli A, Helli P 2005 The pulmonary biology of isoprostanes. Antioxid Redox Signal 7:244-255

18. Goil S, Truog WE, Barnes C, Norberg M, Rezaiekhaligh M, Thibeault D 1998 Eight-epi-PGF2alpha: a possible marker of lipid peroxidation in term infants with severe pulmonary disease. J Pediatr 132:349-351

19. Belik J, Jankov RP, Pan J, Yi M, Chaudhry I, Tanswell AK 2004 Chronic O2 exposure in the newborn rat results in decreased pulmonary arterial nitric oxide release and altered smooth muscle response to isoprostane. J Appl Physiol 96:725-730

20. Lakshminrusimha S, Gugino SF, Mathew B, Nielsen LC, Goldsby T, Morin FC 3rd, Davis J, Russell JA, Steinhorn RH 2005 Intratracheal recombinant human superoxide dismutase (IT-rhSOD) prevents increased pulmonary arterial contractility following ventilation with $100 \%$ O2 in neonatal control and persistent pulmonary hypertension (PPHN) lambs. Pediatr Acad Soc 57:2536

21. Morin FC 3rd, Egan EA, Norfleet WT 1988 Indomethacin does not diminish the pulmonary vascular response of the fetus to increased oxygen tension. Pediatr Res 24:696-700

22. Vento M, Asensi M, Sastre J, Garcia-Sala F, Pallardo FV, Vina J 2001 Resuscitation with room air instead of $100 \%$ oxygen prevents oxidative stress in moderately asphyxiated term neonates. Pediatrics 107:642-647

23. Villamor E, Kessels CG, Fischer MA, Bast A, de Mey JG, Blanco CE 2003 Role of superoxide anion on basal and stimulated nitric oxide activity in neonatal piglet pulmonary vessels. Pediatr Res 54:372-381

24. Steinhorn RH, Morin FC 3rd, Gugino SF, Giese EC, Russell JA 1993 Developmental differences in endothelium-dependent responses in isolated ovine pulmonary arteries and veins. Am J Physiol 264:H2162-H2167 